\title{
The Impact of Body Weight Towards Gross Motor Skill on 4-6 Year Old Children in Rural Preschools
}

\author{
Fitta Nurisma Riswandi, Harun Rasyid \\ Yogyakarta State University, Yogyakarta, Indonesia \\ e-mail: fitta.nurisma2016@ student.uny.ac.id
}

\begin{abstract}
Gross motor skill is a crucial aspect for children in preschool age. This research aims to identify the impact of body weight towards 4-6 year old children's gross motor skill in rural preschools. Participants were divided into 3 groups: 30 underweight children, 30 normal weight children, and 30 overweight children. The result data was divided into two separate sections based on the age group: 4-5 year olds and 5-6 year olds. Based on the ANOVA test, there was no correlation between body weight and gross motor skill in 4- 5 year old children $(p>0.05)$. Inversely, there was a correlation between the two variables in 5-6 year old children $(\mathrm{p}<0.05)$. Children who were considered overweight have the smallest gross motor skill compared to other groups $(M=18.52)$. Conclusion: The data suggest that there is a difference between body weight and gross motor skill in 4-6 year old children in rural preschools. The next research should take a closer look at children's activity both at home and school.
\end{abstract}

Keywords: Preschool, gross motor, body weight, rural, motor skill

\section{INTRODUCTION}

The rapid development of technology has caused majority of preschool children to spend their leisure time indoor. Outdoor physical activities are gradually replaced by indoor activities such as browsing the Internet, playing video games, and watching television (Tsai \& Yang, 2012; Yang, Lin \& Tsai, 2015). Excessive amount fidgeting with gadgets reduces the amount of time that children have to do physical activities. In many cases, this results in obesity. Based on the research by Chaput\& Tremblay (2012), some countries including North America and several cities in Europe have 20-30\% case of overweight and around $5-15 \%$ case of obesity in children between 0-6 years old. In Indonesia, the prevalence of overweight and obese infant is growing higher from $10.3 \%$ to $16.5 \%$ (Rachmi et al, 2016).

Physical activity is crucial for children in their early age in order to avoid overweight and obesity problems. The research shows that children who are physically active have a higher motor skill (Yang, Lin \& Tsai, 2015). It means children need motor skills in order to do physical activities. The right stimulations are required to improve children's motor skills in their early childhood. Thus, NAEYC has included motor skills as an integral standard of a decent early childhood education due to how crucial it is in improving children's health and education (Hamilton \&Liu, 2017).

Motor skills, especially gross motor skills are inseparable from children's daily activities such as playing outside, sports, and other physical activities. Gross motor skills are movements that involves large muscles that enables children to move differently like running and jumping (Jahagirdar et al, 2016; Gallahue \& Ozmun, 2006). Motoric development can affect other developments such as cognitive, social and physical development throughout someone's life (Payne \& Isaacs, 2013). Motor activities are crucial to achieve and maintain health in both children and adults (Colella\&Morano, 2011). Among the factors that affect motor 
development in childhood are growth \& maturity (Louie \& Chow, 2013). Therefore it is very important to provide as many opportunities as possible for children to practice motoric activities that are suitable to their age and gross motor skills (Shala, 2009).

A research by Yang, Lin \& Tsai (2015) connected gender, age, and Body Mass Index (BMI) to the development of locomotor skills and object controls. According to that research, age is the only factor that has significant impact towards locomotor skills, object controls, and basic motor skills. Sex and BMI have very limited impacts towards those three categories. The difference from previous research in regards to BMI variable is because many other different items were added to various tests, the number of tests, and how BMI was categorized. Another researh by Hamilton \& Liu (2017) shows that there is a negative and significant correlation between BMI and motor skills competence.

Based on researches about motor skills in relation with preschool area (Shala\&Bahtiri, 2011), socioeconomi (Hamilton \& Liu, 2017; Lang et al, 2013), body weight (Kim \& Lee, 2016; Nervik et al, 2011; Morano et al, 2011; Yang, Lin \& Tsai, 2015), age (Kakebeeke et al, 2012; D'Hondt, 2011), and gender (Kakebeeke et al, 2012; Burn et al,2017), the instrument used in Yang, Lin \& Tsai (2015), Khalaj\&Amri (2014), and Kim \& Lee (2017) was TGMD-2. This research, on the other hand, uses The Frost-Wortham Developmental Checklist in order to compare the result with other researches and identify how the research instrument plays role to the outcome. This research aims to identify the effect of body weight towards gross motor skills, others use body weight predictors without evenly grouping participants into different body weight groups (underweight, normal, overweight \& obese).

Two researches that connects motor skills with body weight (Nervik et al, 2011; Morano et al, 2011) stated that children with high BMI struggle in their gross motor skill compared to children with normal weight. In Yang, Lin \& Tsai (2015) research, it was stated that there is no significant difference between underweight, normal, and overweight children in terms of gross motor skills, locomotor skills, and object controls. This might be caused by the lack of control in the number of participants in the low BMI group (underweight) in the sample. This limitation can be used by future researchers by including low BMI group and recruiting same number of participants in each category.
The research tested out the effect of body weight, which is categorized into three groups: underweight, normal, and overweight. The reason why the researchers choose rural area is because they are rarely touched by researchers. This research aims to establish the correlation between body weight and gross motor skills in 4-6 year old preschool children in rural areas.

H1. Whether there is a difference between gross motor skill and body weight in 4-6 year old children.

H2. How the body weight variable affects gross motor skill in 4-6 year old children.

\section{METHOD}

\section{Participant}

This study uses purposive sampling technique by recruiting 90 children, evenly divided into underweight, normal, and overweight groups. The participants are between 48-72 months old from 4 different preschools in rural areas.

\section{Instrument}

This research uses The Frost-Wortham Developmental Checklist to measure gross motor skill in participants. The Frost-Wortham Developmental Checklist (Wortham, 2006) is designed to assess children between 0 to 6 years old. Assessment method with score criteria ranging from scores 1-3 like 1 = introduction, 2 = development, and $3=$ master

Table 1. Anthropometric policy from Indonesia's Ministry of Health

\begin{tabular}{lllllll}
\hline \multirow{2}{*}{$\begin{array}{l}\text { Age } \\
\text { (yr.) }\end{array}$} & \multicolumn{2}{l}{ Underweight } & \multicolumn{2}{l}{ Normal } & \multicolumn{2}{l}{ Overweight } \\
\hline $4-5$ & $<12.7$ & $<13.0$ & $12.7-$ & $12.9-$ & $>18.8$ & $>18.3$ \\
& & & 18.8 & 18.3 & & \\
$5-6$ & $<12.7$ & $<13.0$ & $12.7-$ & $13.0-$ & $>17.0$ & $>16.7$ \\
& & & 17.0 & 16.7 & & \\
\hline
\end{tabular}

\section{Procedure}

The research group consists of one doctoral in early childhood education and one master's students in early childhood education. Before conducting tests, the researchers discussed the best instrument to use. The discussion covered the best practices and how to use the measuring instrument went on for 4 days. The researchers then proceeded to conducting outdoor tests by leveraging available outdoor physical activities. The equipments used during the 
tests were: body weight scale, measuring tape, three plastic balls, plank boards and a skipping rope. The tests were conducted in the morning when subjects and environment are at a conducive state. The researchers split up into two groups to measure the gross motor skill of 4-5 year old and 5-6 year old children group. The researchers arrived at the venue 30 minutes earlier to prepare the testing process. The children were instructed to form lines and listen to the instruction given by researchers carefully. The researchers also demonstrated the instructed practice twice to the children in order to give clearer examples. As a compensation for their participation, the researchers provided a carton milk for each participant.

\section{Analysis}

All statistic analysis was processed using IBM SPSS v. 23. Descriptive statistics from body weight variable were calculated by reporting the mean and standard deviation. The normality assumption was calculated using KolmogorovSmirnov test. One-Way ANOVA was used to calculate the difference of children's body weight and the impact towards gross motor skills. The conclusion was drawn based on the value of $\mathrm{p}$, if $p<$ 0.05 , then $\mathrm{H} 1$ can be accepted.

\section{RESULT}

The child respondents included in this study were 90 children, with $46.67 \%(n=42)$ girls and $53.33 \%(\mathrm{n}=48)$ boys. Percentage of number of children by $4-5$ years old $47.78 \%$ and 5-6 years old $52.22 \%$ (Table 1). Based on the results of the analysis using ANOVA One Way, it was found that there was a significant difference between weight and gross motor ability, so hypothesis 1 was acceptable (phitung $=0.035<0.05$ ). However, when viewed from the value of R2 donation given variable weight to gross motor skills children 4-6 years old is very small $(\mathrm{R} 2=0.008)$. Others may be influenced by other factors.

Table 2. ANOVA results of body weight influence gross motor skills

\begin{tabular}{llrl}
\hline \multicolumn{1}{c}{ Variabel } & $\mathrm{R}^{2}$ & $\mathrm{~F}$ & $\mathrm{Sig}$ \\
\hline $\begin{array}{l}\text { Gross motor } \\
\text { abilities }><\text { Weight body }\end{array}$ & 0.008 & 3.495 & .035 \\
(Underweight, Normal, & & & \\
\&Overweight) & & & \\
\hline
\end{tabular}

\section{4-5 years old}

Scores of gross motor skills in children 4-5 years old who have underweight and normal higher than those with overweight. Gross motor skills in children 4-5 years old did not have significant differences with weight that included underweight, normal and overweight $(p=0.915, p>0.05)$. It can be seen in the mean score on the overall assessment of children 4-5 years old with a underweight, normal weight and overweight body difference is not too much (see figure 1). Based on Figure 2 it can be seen that there is a difference between gross motor skills of boys and girls in rural preschools. In children 4-5 years old gross motor skills boys ( $\mathrm{M}=$ 20.29) are better than girls $(M=18.05)$ in rural preschool.

\section{5-6 years old}

In the score of children 5-6 years old gross motor abilities of children who have normal

weight is higher compared with children who are underweight and overweight. Gross motor skills in children 5-6 years old have significant differences in body weight that includes underweight, normal, and overweight $(\mathrm{p}=0.001, \mathrm{p}<0.05)$. The differences in these variables are particularly found in the ability to jump on both feet ( $\mathrm{p}=0.001, \mathrm{p}<0.05)$, walking on the board of the tributaries forward and backward $(\mathrm{p}=0.16, \mathrm{p}<0.05)$, and down the stairs with alternating legs $(\mathrm{p}=0.026, \mathrm{p}<0.05)$.

Gross motor skills of children 5-6 years old with normal weight $(M=21.61)$ have the highest value compared with gross motor abilities in children with underweight and overweight (see figure 1). Furthermore, when seen from Figure 2 in rural preschools gross motor abilities in boys $(\mathrm{M}=$ 19.5) were better than girls $(M=18.6)$.

\section{Gross Motor Skill}

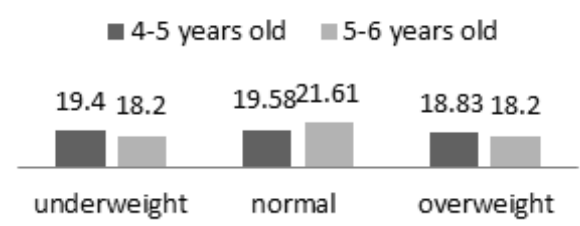

Fig. 1. Average mean gross motor abilities of children who have underweight, normal weight, and overweight are classified by age 


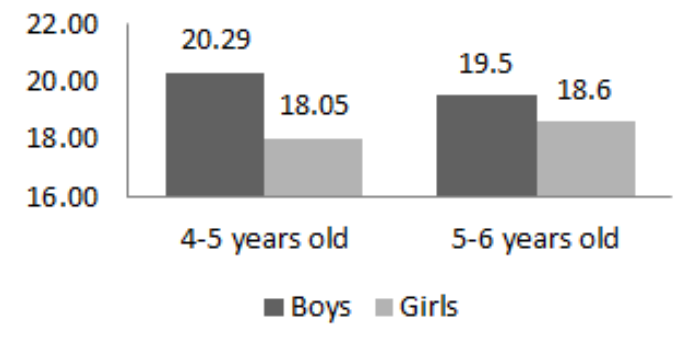

Figure 2. Average mean gross motor abilities of children who have underweight, normal weight, and overweight are classified by sex

Table 3. Activity Gross Motor Skill 4-5 years

\begin{tabular}{|c|c|c|c|c|c|c|c|}
\hline \multirow{2}{*}{ Activity } & \multicolumn{2}{|c|}{ Underweight } & \multicolumn{2}{|c|}{ Normal } & \multicolumn{2}{|c|}{ Overweight } & \multirow[b]{2}{*}{$\mathrm{p}$} \\
\hline & $\mathrm{M}$ & SD & M & SD & $\mathrm{M}$ & SD & \\
\hline \multicolumn{8}{|c|}{ Level IV (4-5 years) } \\
\hline $\begin{array}{l}\text { Balances on } \\
\text { one foot }\end{array}$ & 2.4 & 0.59 & 2.35 & 0.70 & 1.83 & 0.40 & .148 \\
\hline $\begin{array}{l}\text { Walks a } \\
\text { straight line } \\
\text { forward and } \\
\text { backward }\end{array}$ & 1.8 & 0.61 & 2 & 0.5 & 1.5 & 0.54 & .174 \\
\hline $\begin{array}{l}\text { Walks a } \\
\text { balance beam }\end{array}$ & 2.3 & 0.65 & 2.23 & 0.56 & 2.33 & 0.51 & .922 \\
\hline $\begin{array}{l}\text { Climbs steps } \\
\text { with alternate } \\
\text { feet without } \\
\text { support }\end{array}$ & 2.15 & 0.58 & 2.17 & 0.39 & 2.16 & 0.98 & .991 \\
\hline $\begin{array}{l}\text { Climbs on a } \\
\text { jungle gym }\end{array}$ & 2.6 & 0.50 & 2.52 & 0.51 & 2.5 & 0.54 & .877 \\
\hline $\begin{array}{l}\text { Skips } \\
\text { haltingly }\end{array}$ & 2.2 & 0.83 & 2.05 & 0.65 & 1.66 & 0.81 & .336 \\
\hline $\begin{array}{l}\text { Throws, } \\
\text { catches, and } \\
\text { bounces a } \\
\text { large ball }\end{array}$ & 1.9 & 0.64 & 1.82 & 0.64 & 2.5 & 0.55 & .079 \\
\hline $\begin{array}{l}\text { Creates } \\
\text { recognizable } \\
\text { block } \\
\text { structures }\end{array}$ & 2.25 & 0.63 & 2.47 & 0.62 & 2 & 0.63 & .269 \\
\hline $\begin{array}{lr}\text { Rides } & \text { a } \\
\text { tricycle } & \text { with } \\
\text { speed } & \text { and } \\
\text { skill } & \end{array}$ & 1.85 & 0.59 & 1.94 & 0.56 & 2.33 & 0.82 & .244 \\
\hline Total score & 19.4 & 4.09 & $\begin{array}{l}19.5 \\
8\end{array}$ & 3.16 & $\begin{array}{l}18.8 \\
3\end{array}$ & 4.35 & .915 \\
\hline
\end{tabular}

Table 4. Activity Gross Motor Skill 5-6 years

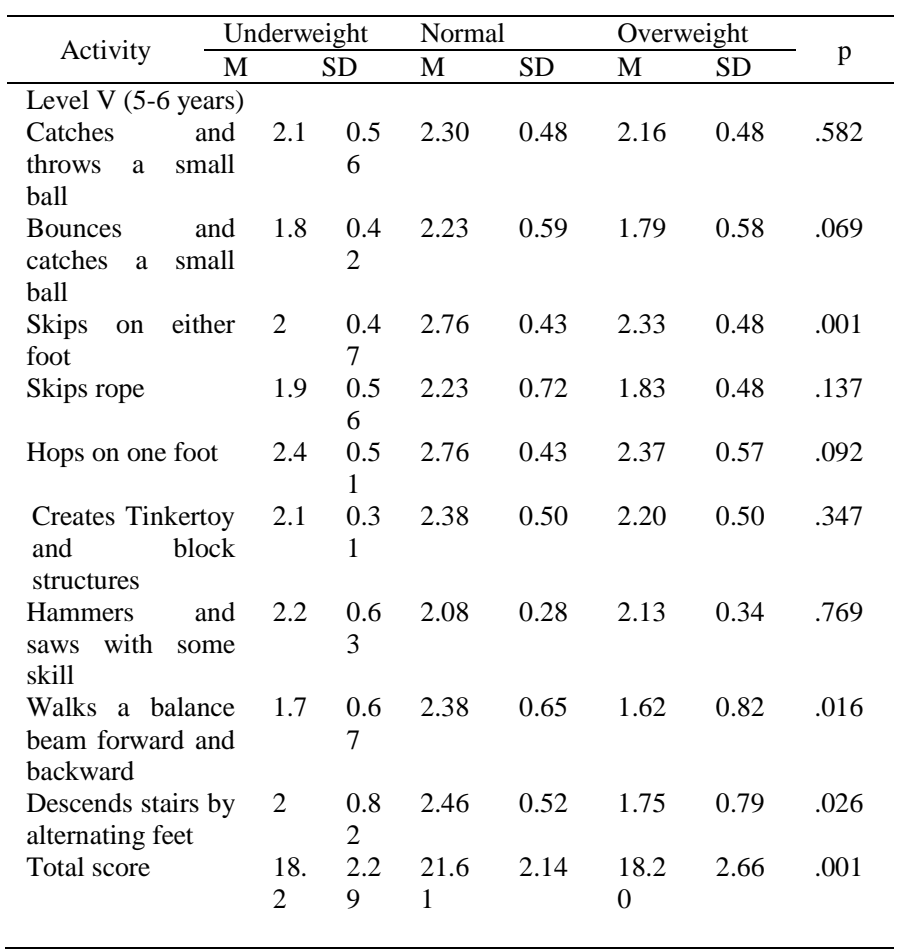

\subsection{Discussion}

Although there are some gross motor skills items that do not have differences in the child's weight, the total overall gross motor skills have differences in weight (underweight, normal, overweight). It was obtained from the data analysis using ANOVA that the variable of gross motor skills with body weight has difference $(\mathrm{p}<0.05)$.

The differences in the results of this study between gross motor skills and body weight differed from those reported by Yang, Lin \& Tsai (2015) focusing on locomotor skills, object-control skills, and fundamental motor skills with respect to gender, age and Index Body Mass (IMT) involving 1,200 preschoolers aged between three and seven of 12 preschools across Taiwan and measured using TGMD-2. The results show that BMIs have no difference between underweight, normal and overweight groups. This is supported by the results of research conducted by Nervik, et al (2011), which aims to determine the relationship between obesity and gross motor development in children 3-5 years old as many as 50 children using the Peabody Developmental Motor Scales, 2nd edition (PDMS2 ). The results show that there is no significant relationship. However, these findings are different 
from those of Khalaj \& Amri (2014) which focus on knowing gross motor skills mastery among preschoolers and under-five children; and the differences that exist between these two groups. In this study used the TGMD-2 Instrument used to assess the gross motor performance of all participants. The median age of preschoolers was 4.87 (SD: 0.49), and for primary school children was 7.34 (SD: 0.63). The results of this study suggest that there is a significant difference in the performance of gross motor skills between preschool obese children and obese primary school children. Further research conducted by Hamilton, Liu \& ElGarhy (2016) which aims to determine the relationship between motor competence and BMI in Hispanic preschoolers from low SES background. As many as one hundred and forty-eight preschool SES low Hispanic children $($ men $=81$, women $=67$ participated in the study All children were measured by gross motor skill using the Peabody Developmental Motor Scales, 2nd edition (PDMS2). Significant negative correlations were found between IMT and visual motor integration. Based on several studies of the above studies there are different results between gross motor skill with body weight. This can be considered in subsequent research to pay attention to the test equipment and the number of activities performed by early childhood.

The results of the present study show that overweight has poorer motor skills performance than underweight and normal group. Similarly, Nervik et al (2011) found that overweight or obese children were more likely to experience lower gross motor skills than those who did not. Furthermore Khalaj \& Amri (2014) found that obese children had grosser motor performance that was lower than normal weight. However, in previous studies conducted by Yang et al (2015) motor skills in children with overweight have a higher score than in normal and underweight children. The weight-related differences between prior research and current research may be due to the use of different assessment tools and items. It also needs to consider also the differences in the area where the child lives and the socioeconomic family.

\section{CONCLUSION}

Children who have overweight and underweight of gross motor skills there is no difference in some activities. In children 4-5 years old all activities in children who have underweight, normal or overweight does not have a difference. While in children 5-6 years old there are significant differences some activities in children who have underweight, normal or overweight do not have differences, including: catch and throw a small ball, reflect and catch a small ball, jump with a rope, jump with one foot, build buildings from blocks and use hammers and chainsaws skillfully.

In the next study is expected to not only look at the child's weight but also from the intensity of the number of activities performed by the child, how the physical activity of parents and eating patterns consumed by children.

\section{REFERENCES}

[1] Chow, B. C., \& Louie, L. H. T. (2013). Difference In Children's Gross Motor Skills Between Two Types Of Preschools 1. Perceptual \& Motor Skills: Motor Skills \& Ergonomics, 253-261.

[2] Colella, D., \& Morano, M. (2011). Gross motor development and physical activity in kindergarten age children, 6, 33-36.

[3] Chaput, J. ., \& Tremblay, A. (2017). Obesity at an Early Age and Its Impact on Child Development, $1-5$.

[4] Gallahue, D.L.(2006). Understanding motor development: Infants, children, adolescents, adults. New York: McGraw Hill.

[5] Gottschling-lang, A., Franze, M., \& Hoffmann, W. (2013). Associations of Motor Developmental Risks with the Socioeconomic Status of Preschool Children in North-Eastern Germany. Hindawi Publishing Corporation Child Development Research, 2013.

[6] Hamilton, M., \& Liu, T. (2017). The Effects of an Intervention on the Gross and Fine Motor Skills of Hispanic Pre-K Children from Low SES Backgrounds. Early Childhood Education Journal, 0(0), 0.

[7] Hamilton, M., Liu, T., \& ElGarhy, S. (2016). The Relationship Between Body Weight and Motor Skill Competence in Hispanic Low-SES Preschool Children. Early Childhood Education Journal.

[8] Hondt, E. V. A. D., Deforche, B., Vaeyens, R., Vandorpe, B., Vandendriessche, J., Pion, J., ... Lenoir, M. (2011). Gross motor coordination in relation to weight status and age in 5- to 12 year-old boys and girls: A cross-sectional study. International Journal of Pediatric Obesity, 32(December 2009), 556-564. 
[9] Jahagirdar, I., Venditti, L. A., Duncan, A., Reed, N., Jahagirdar, I., Venditti, L. A., ... Reed, N.' (2017). Exploring the relationship between participation in a structured sports program and development of gross motor skills in children ages 3 to 6 years. Journal of Occupational Therapy, Schools, \& Early Intervention, $0(0), 1-10$.

[10] Kakebeeke, T. H., Caflisch, J., Locatelli, I \& Rousson, V., \& Jenni, O. . (2012). Improvement in gross motor performance. Perceptual \& Motor Skills, (32473), 795-806.

[11] Khalaj, N., \& Amri, S. (2014). Early Child Development and Care Mastery of gross motor skills in preschool and early elementary school obese children. Early Child Development and Care, (December 2014), 795-802.

[12] Kim, C., \& Lee, K. (2016). The relationship between fundamental movement skills and body mass index in Korean preschool children. European Early Childhood Education Research Journal, 0(0), 1-8.

[13] Morano, M., Colella, D., \& Caroli, M. (2011). Gross motor skill performance in a sample of overweight and non-overweight preschool children. International Journal of Pediatric Obesity, 6, 42-46.

[14] Nervik, D., Martin, K., Rundquist, P., \& Cleland, J.' (2011). The Relationship Between Body Mass Index and Gross Motor Development in Children Aged 3 to 5 Years, (2).
[15] Nikolić, I., Mraković, S., \& Kunješić, M. (2016). Gender Differences of Preschool Children in Fundamental Movement Skills. Croatian Journal of Education, 18(1), 123-131.

[16] Payne, V.G \& Isaacs, L.D. (2012). Human motor development : a lifespan approach. New York: McGraw Hill.

[17] Rachmi CN, Agho KE, Li M, Baur LA (2016) Stunting, Underweight and Overweight in Children Aged 2.0-4.9 Years in Indonesia: Prevalence Trends and Associated Risk Factors. PLoS ONE 11(5): e0154756.

[18] Shala, M. (2009). Early Child Development and Care Assessing gross motor skills of Kosovar preschool children. Early Child Development and Care, (November 2014), 37-41.

[19] Shala, M., \& Bahtiri, A. (2011). Early Child Development and Care Differences in gross motor achievements among children of four to five years of age in private and public institutions in Prishtinë , Kosovo. Early Child Development and Care, (March 2015), 37-41.

[20] Tsai , C. Y. , \& Yang, S. C. ( 2012 ) Study on the appearance of childhood games. Journal of Educational Studies , 46 ( 1 ), 1 - 19 .

[21] Wortham, Sue Clark. (2006). Early childhood curriculum:developmental bases for learning and teaching. New Jersey: PEARSON

[22] Yang, S., Lin, S.-J., \& Tsai, C.-Y. (2015). Effect of sex, age, and bmi on the development of locomotor skills and object control skills among preschool children 1. Perceptual \&
Motor 